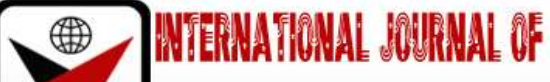

ISSN 2278-0211 (Online)

\section{Using the Constructivist Approach to Enhance Students' Competence in Solving Word Problems Involving Linear Equations in One Variable}

\author{
Abdul-Rahaman Yakubu, \\ Tutor, Department of Mathematics \& ICT, E. P. College of Education, Bimbilla, Ghana
}

\begin{abstract}
:
The objective of the study is to improve the proficiency of students from business stream of Tamale Girls Senior High School (TGSHS) regarding the solving method of linear equations related problems. An action research-based study has been done on 35 female students from a mean age of $16^{+}$years. Both pre-test and post-test have been applied for collecting data. Mean, standard deviation and t-test have been applied for the analysis. The guided discovery approach has been applied over here. Result indicates significant differences between the traditional teaching method and the guided discovery approach for teaching mathematics at Tamale Girls SHS. This study also suggested more training, workshops, seminars can be arranged by teachers to encourage students of guided discovery approach in teaching mathematics.
\end{abstract}

Keywords: Constructivist theory, competence, linear equations, word problems, guided discovery

\section{Introduction}

The main aim of teaching and learning mathematics in Ghanaian schools is to equip learners with the ability to describe, investigate and eventually solve mathematical problems through the use of their mathematical knowledge, skills and techniques. (Curriculum Research and Development Division -CRDD 2007).The application of mathematics is evident in all fields of study and at the job market. Mathematics is accepted worldwide as a powerful tool for national development, yet most students perceive it to be abstract in nature and therefore do not commit themselves fully to the study of mathematics. Word problem had been defined by Verschafel, Greeer, and De Corte. (2000), where answer can be obtained by application of mathematical operations. It is aimed to develop the ability and talent of the students (De Corte, Vershafel, Dewin\&Mulhern, 1989). Mayer \& Hegarty (1996), highlighted that calculation algorithms are being successfully used by students, but they are not able to solve word problems which need the same algorithms. Geary (1994:15) says "children make errors when solving word problems than solving comparable number problems". A study by Adu, Assuah and Asiedu-Addo (2015) exposed that problem solving depends on comprehension, interpretation, encoding skills. One call for classroom attention to problem solving strategies came from the National Council of Teachers of Mathematics (NCTM, 2000:5), which contended in its widely-read and cited principles and standards of school mathematics that, "students need to develop a range of strategies for solving problems, such as using diagrams, looking for patterns or trying special values or cases". These strategies need instructional attention if students are to learn them. The standards also suggested that teachers give students opportunities for the application of problem-solving strategies across all mathematics content areas.

\section{Literature Review}

This research work is framed within Piaget's (1965) constructivist theory. A basic tenant of constructivism is active learning. Zoltan Dienes states, "One of the first things we should do in trying to teach a learner mathematics is to think of different concrete situation with a common essence. Children will learn by acting on a situation" (Sriraman \& Lesh, 2007, p61). How effectual or instrumental the learner's knowledge structure is in facilitating thinking in the content field is the measure of learning (Bednar, Cunnigham, Duffy, \& Perry, 1992).According to Stanic and Kilpatrick (1989), problems have occupied a central place in the school mathematics curriculum since antiquity, but problem solving has not. Traditionally we use problems as a means of teaching mathematics. More specifically, problems have most often been used as a vehicle to practice facts, rules, formulas, or procedures (Baroody, 1993).Word problems are defined as the set of problems which in the educational contexts are solved through the application of various elementary arithmetic operations successively combined with one another until a result is obtained (arithmetic procedure) or through the formulation of equations which are later solved to obtain a result (algebraic procedure) (Cerdan, 2008). Cerdan claims that it is not the structure of the problem which determines whether it is arithmetic or algebraic but rather the process 
widely spread across different educational cycles. Word problems are first introduced at the Primary school level as with arithmetic operations. At the Senior High School level, a new approach for solving word problem that is algebra is introduced, and this is a much more effective approach since it can be applied to problems of all kinds. Different theorists have also defined word problems in various ways. Some mathematics educators defined word problems by their structure, appearance and the inbuilt assumptions behind them (Lesh, Post \& Behr,1987).

Word problems do have an easily recognizable structure and some assumptions are always made by both students and teachers such as assuming that information not mentioned in the problem statements will not be required for successful problem solving. According to Boote, (1998) a word is defined by its use as a tool rather than by its characteristics. He went on further to say word problems can be useful as a means of illustrating practical use of an algorithm or a modeling tool in Physics and Statistics.

Polya (1962 pg v) described problem solving as "finding a way out of a difficulty, a way around an obstacle, attaining an aim which was not immediately attainable" He further specified this conception of problems and problem solving in terms of mathematics: "Our knowledge about any subject consists of information and know-how...What is knowhow in mathematics? The ability to solve problems - not merely routine problems but problems requiring some degree of independence, judgment, originality, creativity" Polya (1962 pgvi). Further, problem solving has been highlighted as a wide array of cognitive actions through with students can use their knowledge and previous experience (Lester and Kehle,2003). What does it mean for students to organize previous knowledge and experiences to generate new knowledge? It is clear that if students are to be engaged in problem solving activities, they need to develop a way of thinking, consistent with mathematical practices in which problems or tasks are seen as impasses that need to be examined in terms of questions. Thus, students need to construct their own learning.

Miller and Margaret (1998) said that one of the main reasons for learning mathematics is to be able to use it in solving practical problems. For most students however, learning how to apply mathematical skills to real life situation is the most difficult task to them. A common difficulty with word problem is trying to do everything at once. It is usually best to approach the problem in stages. But of course, the solution of a word problem depends upon the student's ability to translate the word problem into mathematical equations. Comprehension, strategy know-how, transformation process skill and solution are the phases to solve a problem (Newman, 1983). Schoenfeld (1985) talked about four phases. Knowledge, control and beliefs, and effects are the four phases for problem solving as per Kroll and Miller, (1993). Along with phases traits, disposition, and experiential background drive problem solving approach (Lester, 1994). In the early 1970s research tended to attribute difficulties in solving problems to the various task variables such as content and context variables, structure variables, syntax variables and heuristic behavior variables(Goldin \& McClintoch, 1979). In other words, the knowledge one possesses, one's disposition and one's experiential background often influence problem solving performance. These were also evident in a study conducted in Singapore by Kaur (1995) and Lee (2001). Kaur indicated that Singapore's students experienced problem-solving difficulties such as:

- $\quad$ Lack of comprehension of the problem posed

- Lack of strategy knowledge

- Inability to translate the problem into a mathematical statement

In Ghana, the educational reform review committee (Anamuah-Mensah, 2002) recommended an investigatory method of teaching at the pre-tertiary level of education. The committee suggested that investigatory method need to be used as this encourages the teaching of mathematics content through activities that students encounter in real life situations

Mayer, (2003) states that discovery method of teaching is a teaching technique that encourages students to take a more active role in their learning process by answering a series of questions or solving problems designed to introduce a general concept. The discovery method is based on the notion that learning takes place through classification and schema formation (Gallenstein, 2004).

Mosston (1972) specifies ten cognitive operations that might take place as the learner engages in active inquiry: recognizing data, analyzing, synthesizing, comparing and contrasting, drawing conclusions, hypothesizing, memorizing, inquiring, inventing, and discovering.

The above discussions stand to mean that students' inability to solve word problems should be the sole responsibility of both the teacher and the student concerned. There are technicalities in word problems which students need to know before equation in word form is given to them. The semantic structure should be explained to the students to help them easily interpret word problems of any form. If students are taught the steps on how to interpret word problems into mathematical statements then they stand a better chance of solving them correctly.

Teachers of mathematics should therefore take the responsibility of taking their students through the required steps and strategies for solving word problems in mathematics for them to acquire the basic steps and skills required.

\section{Significance of the Study}

Overlooking the relevance of this research may not be laudable. The findings of this study are expected to reveal some of the deficiencies existing in the teaching and learning of mathematics especially solving word problems and will also serve as a guide for teachers to vary their methodology to enable students understand word problems involving linear equation in one variable. Furthermore, the finding of the research will help sharpen most of the students' analytical skills in understanding word problems. It will promote and sustain students' interest to learn mathematics as well as motivate slow learners to improve upon their learning. This study will help deepen students' understanding of modeling word problems into algebraic equations and better equip those who plan curriculum and teach students to meet the needs of Senior High School students in mathematics. 


\subsection{Purpose of the Study}

The purpose of the study was to investigate the effect of the language used in word problems on linear equations in one variable has on Business students of TGSHS when modelingit into algebraic equations. Also, the study sort to determine the differences, if any, exist in student achievement on translating and solving word problem on linear equations in one variable using discovery method.

\subsection{Research Questions}

- What effect does the language used in word problems on linear equations in one variable have on Business students of TGSHS when modeling it into algebraic equations?

- What differences, if any, exist in students' achievement on modeling word problems into algebraic equation and solving it using discovery method?

\subsection{Research Hypothesis}

- $\mathrm{H}_{\mathrm{o}}$ : the pre-test and the post-test scores of students when taken through the use of discovery method are equal.

- $\mathrm{H}_{\mathrm{a}}$ : statistical significant difference exists between the pre-test and the post-test scores of students when taken through the use of discovery method.

\section{Methodology}

\subsection{Research Design}

A research design is a "plan, recipe or blueprint for the investigation" (de Vos, 2002:165) and thus offers a clear description of how the research is going to be conducted. This gives an indication of the procedures that will be followed in the sampling and data collection in order to reach the research aim and objectives. The ultimate goal of a good research design is to provide a credible answer to the research question (Macmillan \& Schumacher, 2001).

The model for this study is action research, since it seeks to find solution to students' inability to solve word problems on algebra involving linear equations effectively.

\subsection{Independent and Dependent Variables}

The independent variable was guided discovery approach and dependent variable was the students' pre and posttest achievement scores.

\subsection{Population}

The target population for this study was 450 form one students of Tamale Girls Senior High School (TGSHS) in the Northern Region of Ghana. The school has eighty (80) teaching staff and fifty (50) none teaching staff. The school runs the following academic programmes: Business, General science, General arts and Home economics.

\subsection{Sample}

A sample is a group of subjects or persons selected from the target population. This is a group of individuals with similar characteristics as the target population and is trusted to provide the relevant data as it would be obtained from the whole population. The subjects that were used for the study were 35 Form one Business students of TGSHS with an average age of 16 .

\subsection{Sampling Procedure}

The sampling strategy employed in this study was purposive sampling. The researcher used this strategy because he wanted to get an in-depth knowledge of the problem among the female students. Also, the purposive sampling technique was used to select the students who had problems in solving word problems involving linear equation in one variable. According to Patton (2002), purposive sampling approach is sometimes called judgment sampling and is used to select information for study in depth, thus participants who possess rich information on the problem.

\subsection{Instruments}

Bothpre-test and post-test methods have been designed on the basis of algebraic word problems (see appendices A \& B). Questions have been selected to make collection, organization, interpretation, and analysis process smooth. Both these tests have been used for evaluation purpose. Marking has been done on the basis of 100 marks.

\subsection{Validity and Reliability}

In order to be sure of the validity of the test items, the researcher involved two members of the mathematics/ICT department of the researcher's college in checking and ensuring that the test items were both face and content valid which they really confirmed. The tutors concluded that the items met the SHS students' standard and hence cleared it for administration, having compared it to the SHS mathematics syllabus. Reliability of the test items were tested when thirty (30) SHS students were involved in the writing of the pilot test. The 30 subjects of the pilot test were not part of the actual study sample. Reliability coefficient of 0.88 was recorded using split half method. 


\subsection{Pilot Testing}

Prior to data collection, the achievement test was conducted as part of pilot phase. This allowed an examination of the appropriateness of the items and administration procedures as well as the appropriate time frame for completion of each skill. The pilot testing occurred in form one (1) class of Bimbilla Senior High School.

After the testing was complete, the students' performance was analyzed and necessary changes made to the assessments and administration procedures. Changes to the assessment included: clarification of directions, implementing an appropriate time frame for completion, item arrangement, and item appropriateness. Clarification of direction was assessed through student feedback and observations of student understanding of the task directions. The appropriate frame for the assessment was assessed by timing the amount of time it takes for the pilot class to complete the assessment and student feedback. The appropriateness of the items was assessed by reviewing the item discrimination and item difficulty for each problem.

Minor changes were made to the assessment after the pilot testing. The directions were clarified as to make the instructions more direct for the students. Items were rearranged in four skill sections of the test to maintain the easy-todifficult progression of items.

\subsection{Pre intervention}

Students were given pre-test containing items that required them to translate word problems into algebraic equations and solving the equations as well. The pre-test (see appendix A) was aimed at finding out the students' level of competence in translating word problems into algebraic linear equations and how to solve the modeled equations as well. After administering the pre-test, the researcher observed a generally low performance of the students in terms of modeling algebraic linear equations out of word problems, which was below the average score. The indication was that, students were not able to interpret words like sum, difference, product of, less than, quotient, etc.

\subsection{Intervention Activities}

Results of the pre-test showed that the students have problem with translating algebraic word problems into algebraic equations and solving the equation as well.To address these challenges of the students, a series of intervention activities using the constructivist approach of teaching and learning (guided discovery) were organized by the researcher for the students.

According to Mosston and Ashworth (2002), guided discovery is characterized by convergent thinking. The instructor devises a series of statements or questions that guide the learner, step by logical step, making a series of discoveries that leads to a single predetermined goal. In other words, the instructor initiates a stimulus and the learner reacts by engaging in active inquiry thereby discovering the appropriate response. Generally, one can say that successful discovery learning is related to reasoning from hypotheses, to applying a systematic and planned discovery process (like systematic variation of variable values), and to the use of high-quality heuristics for experimentation (de Jong, \& van Joolingen, 1998).

The findings from the pre-test result necessitated the design and implementation of an intervention. The study adopted a guided discovery method of teaching to help address students' challenges in solving word problems on linear equations. The instructions for the intervention activities were as follows:

- $\quad$ Read the problem thoroughly to understand what you are solving for.

- Identify the unknown in the problem and assign a variable such as $\mathrm{x}$ for it

- Translate the problem into an equation using key terms to describe the mathematical operations required. Terms such as 'increased by', 'total of', 'more than', 'combined together', 'sum', 'added to', etc. signal operations that involve ADDITION. Phrases such as 'decreased by', 'difference between', 'less than', 'reduced by', etc. means the operations involve SUBTRACTION. Words and phrases such as 'of', 'product of', 'times', 'multiplied by', etc. indicate operation that require MULTIPLICATION. Terms such as 'per', 'out of', 'quotient of', etc. indicates operations that require DIVISION. When words like 'is' or 'will be' are featured in a word problem, they indicate EQUAL TO.

- Solve the equation using appropriate methods

- $\quad$ Check the proposed solution by plugging the answers into the equation. If both sides of the equation are equal, you have the solution. If one side of the equation is not equal to the other side check your work and revise your solution to the problem.

\subsection{Administration of the Test}

Both the pre-test and post-test have been used to find out the strength as well as the weakness of the students. Students were asked to solve the questions without any consultation form peer groups within a period of 45 minutes for each set.

\subsection{Data Analysis}

According to Cooper and Schindler (2006), quantitative research attempts precise measurement of something and it determines facts and figures. They went on to say that quantitative analyses are used to figure out exactly what happened or how often things happen. Hence this study used quantitative data analysis. After the data was collected, it was then analyzed using descriptive and inferential statistics. The researcher undertook inferential analysis of the pre-test and post-test, and the data used for this analysis were the scores obtained by the students in both tests. Statistical Package for Social Scientist (SPSS) was employed by the researcher to obtain the results of the analysis. 


\section{Results}

- Research Question 1: What effect does the language used in word problems on linear equations in one variable

have on Business students of TGSHS when modeling it into algebraic equations?

Table 1 shows the frequency distribution in percentages of the marks obtained by the students in both pre-test and posttest. This suggests that the language used in word problems has negative effect on the students' ability to translate word problems into algebraic equations.

\begin{tabular}{|c|c|c|c|c|c|}
\hline \multicolumn{2}{|c|}{ PRE-TEST } & \multicolumn{3}{c|}{ POST-TEST } \\
\hline Score & Frequency & Percentage & Score & Frequency & Percentage \\
\hline $1-10$ & 3 & 8.6 & $1-10$ & 0 & 0 \\
\hline $11-20$ & 6 & 17.1 & $11-20$ & 0 & 0 \\
\hline $21-30$ & 8 & 22.9 & $21-30$ & 1 & 2.9 \\
\hline $31-40$ & 13 & 37.1 & $31-40$ & 4 & 11.4 \\
\hline $41-50$ & 3 & 8.6 & $41-50$ & 9 & 25.7 \\
\hline $51-60$ & 2 & 5.7 & $51-60$ & 8 & 22.9 \\
\hline $61-70$ & 0 & 0 & $61-70$ & 1 & 2.9 \\
\hline $71-80$ & 0 & 0 & $71-80$ & 3 & 8.6 \\
\hline $81-90$ & 0 & 0 & $81-90$ & 8 & 22.9 \\
\hline $91-100$ & 0 & 0 & $91-100$ & 1 & 2.9 \\
\hline Total & $\mathbf{3 5}$ & $\mathbf{1 0 0}$ & Total & $\mathbf{3 5}$ & $\mathbf{1 0 0}$ \\
\hline
\end{tabular}

Table 1: Frequency Distribution of Pre-Test Scores in Percentages

From table 1 the pre-test performance was not good as compared to the post-test. For instance, all the 35 (100\%) students in the pre-test scored below 61 marks as compared to 22 students who scored below 61 marks in the post-test. Scoring between 1-20 marks has been obtained by 9 (25.7\%). Marks between 61-100 has been obtained by 13 students $(37.1 \%)$ in the post-test. Post-test result has shown more improvement compared to pre-test.

- $\quad$ Research Question 2: What differences, if any, exist in students' achievement on modeling word problems into algebraic equation and solving it using discovery method?

\subsection{Testing of Hypothesis}

According to Asiedu-Addo, Awanta and Ampiah (2004), testing of hypothesis is mainly concerning with the comparison of means under the two conditions or when matched paired are measured under the same condition. The means of the dependent samples, pre-test and post-test are given in table 4 below. The p-value for the statistical test for the hypothesis was set at $p<0.05$.

\subsubsection{Null Hypothesis, $H_{0}$}

The pre-test and the post-test scores of students at $a=0.05$ level of significance is equal $(p<0.05)$. $\mathrm{H}_{\mathrm{o}}: \mu_{1}=\mu_{2}$

\subsubsection{Alternate Hypothesis, $H_{a}$}

Significant difference exists between the pre-test and the post-test scores of students at $a=0.05$ level of significance $(p<0.05)$. $\mathrm{H}_{\mathrm{a}}: \mu_{1} \neq \mu_{2}$

\begin{tabular}{|c|c|c|c|c|c|c|}
\hline Test & N & Mean & SD & Df & t & Sig \\
\hline Pre-test & 35 & 30.43 & 12.88 & \multirow{2}{*}{34} & -6.973 & 0.000 \\
\hline Post test & 35 & 60.77 & 19.56 & & & \\
\hline
\end{tabular}

Table 2: Paired Sample T-Test of Pre-Test and Post-Test Scores

From Table 2, the results of the paired sample t-test showed significant difference between mean performance scores of Pre-test mean score $(M=30.43, S D=12.88)$ compared to post test $(M=60.77, S D=19.56)$ were statistically different $(t(34)=-6.973, p=.000<.05)$. The post-test scores indicated a change in the performance of the students as compared to that of the pre-test scores in students' performance in solving algebraic word problems. The absolute mean difference was 30.34. This finding indicates that the students' performance was better in the post test than the pre-test hence the guided discovery method actually helps in addressing the word problem in one variable. Hence, the researcher rejects the null hypothesis and accordingly accepts the alternate hypothesis. The analysis further indicates that the pretest scores were between $17.55 \%$ and $43.31 \%$ while the post test scores were also between $41.21 \%$ and $80.33 \%$.

\section{Discussions}

As result of post-test is improving in nature, it is highly suggested that more communication and comprehensions are needed from teachers' side.

\subsection{Revisiting the Research Questions}

The first research question which read: What effect does the language used in word problems on linear equations in one variable have on Business students of TGSHS when translating it into algebraic expressions? 
For the researcher to be able to answer the first research question all the solution set of the 35 female students were carefully scrutinized. It was observed that the poor response to the pre-test items were due to the following:

- Students find it very difficult to formulate the given problem situation into the symbolic algebraic equation. This might be due to lack of correct interpretation of the language used in the question and

- Students could not identify the variables and the relationship that exist between those variables.

These confirm what Kaur (1995) states that Singapore's students experienced problem-solving difficulties such as lack of comprehension, lack of strategy and inability to translate the problem into mathematical statement.

Considering the scores obtained by the students in the pre-test and post-test as shown in table 1, it can be deduced that the performance of the students before the intervention was very low. The respective frequency distributions of the pretest and post-test (see table 1) clearly showed the difference in the scores obtained by the students. In the pre-test (see table 1) for instance thirty (30) out of the thirty-five (35) students scored less than half of the 100 marks for the test which represented $85.7 \%$ of the total number of students. The reason was mainly way of teaching, where students hardly get any chance to apply their skills and comprehensive power but to memorize it.

The students could not analyze simple mathematical word problem and interpret key words, such as "sum" to mean 'add', 'difference' to mean 'subtract', 'product' to mean 'multiply' and 'quotient' to mean divide.Results from the posttest scores by the students as shown in table 1 clearly indicated that the students performed much better as compared to the pre-test. Finding of Mosston (1972) is in the in line with this. From the frequency distribution of the post-test scores (table 1), out of thirty-five students who took part in the test, thirty (30) of them obtained more than half of the total mark of 100 for the test, representing $85.9 \%$ of the total student's number. This clearly indicates improvement. Findings of Lester and Kehle (2003) in line with this. The second research question read: What differences, if any, exist in students' achievement on translating and solving word problem on linear equations in one variable using discovery method?

In finding answer to research question 2, the paired sample t-test was applied using the pretest and the post-test scores. Tables 2 shows the comparative analysis of the pre-test and the post-test results of the whole 35 female participants of TGSHS. From Table 2, the post-test mean score of the students was higher than the pre-test score. The mean for the pre-test was 30.43 while that of the post-test was 60.77 . The analysis shows that there was a significant change in the students' achievement in the post-test scores in solving word problems on linear equations in one variable. The mean difference was significant hence the null hypothesis was rejected at 0.05 alpha level. The researcher can conclude that the change was not by chance but rather came about as a result of the intervention - (the discovery method of teaching/learning by the researcher) which had a positive effect on students' achievement in word problem on linear equations in one variable.

\section{Conclusion}

Mathematics, especially converting word problems to mathematical equations/expressions have become a major problem for many teachers as well as students compared to problem solving. To find out a constructive approach is the main objective behind this study. This study showed that constructive approach is more powerful, which clears that helping students to solve problems by their own is more powerful compared to solve them in an unorganized form. De vries, Zan, Hildebrandt, Edmiaston and Sales (2002) ascertained that teachers who have been habituated to teaching by telling and directing students' work must shift from seeing themselves as central in producing learning to seeing the student as central. This makes students not to interact with each other during lessons. They were also not allowed to learn by discovery.

\section{Recommendations}

The study examined the benefits of the use of guided discovery approach in the teaching and learning of problems involving linear equations in one variable. Based on the results of this study the researcher had these recommendations and suggestions for further studies:

- $\quad$ Students must be guided to read, interpret, analyze and solve various types of word problems.

- Students must be provided with skills to enable them effectively translate word problem into algebraic equations.

- Through continued professional development, more teachers should be sensitized about the strengths and limitations of the use of the discovery method.

- Teachers should be supported as they become acquainted with and use innovative teaching and learning activities.

- To examine the effects of the discovery method using the activities to teach word problems, this study should be replicated with students in mix schools.

\section{Acknowledgement}

The researcher acknowledges with appreciation the assistance offered by the first year, business students of Tamale Girls' Senior High School, selected for this research. The researcher is grateful to the entire staff as well. He also expresses his gratitude to unknown reviewers for their useful comments

\section{References}

i. Anamuah-Mensah., J (2002). Ghana Educational Committee Report Meeting the Challenges of Education in the 21st Century. Accra; Ministry of Education, Ghana. 
ii. Adu, E. Assuah, C.K. \& Asiedu-Addo, S.K. (2015). Students' errors in solving linear equation word problems: Case study of a Ghanaian senior high school. African Journal of Educational studies in mathematics and sciences. Vol. $11,2015$.

iii. Asiedu-Addo, S.K. Awanta, E.K. \& Amppiah, M. (2004). Statistics and probability with computer application. Accra: City publishers; 2004.

iv. Baroody, A. J. (1993). Problem solving, reasoning and communicating, K-8: Helping Children toTthink Mathematically. New York: Merrill.

v. Bednar, A. K., Cunning. D, Duffy, T. M. \& Perry, J. D. (1992) Theory into Practice. How Do

vi. We Link? In Duffy, T. M. \&Jonassen, D. H. (eds); Constructivism and the Technology of Instruction: A Conversation. New Jerey; Lawrence Eelbaum Associates, Inc, Publishers

vii. Boote, D (1998) Physics Word Problems as Exemplars for Enculturation, For the Learning of Mathematics 18(2).

viii. Cerdan, F. (2008) Estudies Sobre la Familla de Problems Arithmetico-Algebraicos. Unpublished

ix. Doctoral Dissertation. Universidal de Valencia

X. Cooper, D., \& Schindler,P. (2006).Business research methods(10ed.). New York, Mc Graw -Hill/Irwin.

xi. Curriculum Research and Development Division-CDDR- (2007). Ministry of Education, Ghana

xii. De Corte, E. Vershaffel, L.,Dewin, L \& Mulhern G(1985). Influence of Rewording Word Problems on Children's Problem. Representations and Solutions. Journal of Educational Psychology, 77, 460-470.

xiii. De Jong, T. \& Van Joolingen W. R. (1998). Scientific Discovery Learning. Review of Educational Research, 68(2).

xiv. De Vos, A. S. (2002). Research at Grass Roots: for the Social Sciences and Human Service

xv. Professions. Pretoria: Van Schaik Publishers.

xvi. De Vries, R., Zan, B., Hildebrandt, C., Edmiaston, R. \& Sales, C. (2002). Developing constructivist early childhood curriculum. New York: Teacher's College pres; 2002

xvii. Gallenstein, N. L. (2004). Creative discovery through classification (early childhood corner). Teaching Children Mathematics, 1, 103- 108.

xviii. Geary, D.C, (1994). Children's Mathematical Development: Research and Practical Applications Washington D.C: American Psychological Association.

xix. Goldin, G. A., \& McClintock, C. E. (Eds.). (1979). Task variables in mathematical problem solving. Columbus, Ohio: ERIC/SMEAC.

xx. Kannae, L.A. (2004). Research Skills Capacity Building for National Teachers' Organization,

xxi. Training Manual. Pan African Teachers Centre, Lome, Togo.

xxii. Kaur, B. (1995). An investigation of children's knowledge and strategies in mathematical problem solving. Unpublished doctoral dissertation, Monash University, Australia.

xxiii. Kroll, D. L., \& Miller, T. (1993). Insights from research on mathematical problem solving in the

xxiv. Middle grades. In D. T. Owens (Ed.), Research ideas for the classroom: Middle grades

xxv. Mathematics (pp. 58-77). NY: Macmillan.

xxvi. Lee, T. Y. (2001). Problem solving in calculus. Unpublished Postgraduate Diploma Dissertation,

xxvii. Nannyang Technological University, Singapore.

xxviii. Lesh, R., Post, T,„\& Behr, M. (1987) Representations and Translations Among Representations in Mathematics Learning and Problem Solving, in Janvier C. (ed) Problems of Students of Representations in The Teaching of Mathematics. Hillsdate New Jersey: Lawrence Erlbaum Associates.

xxix. Lester, F. K. (1994). Musing about mathematical problem-solving research: 1970-1994. Journal for Research in Mathematics Education, 25(6), 660-675.

xxx. Lester, F. K., \&Kehle, P. E. (2003). From problem solving to modeling: The evolution of thinking about research on complex mathematical activity. In: R. Lesh, \& H. Doer (Eds.),

xxxi. Beyond constructivism. Models and modeling perspectives on mathematics problem

xxxii. Solving, learning and teaching (pp. 501-517). Mahwah, NJ: Lawrence Erlbaum associates, Publishers.

xxxiii. MacMillan, J. H. \& Schumacher, S. (2001). Research in Education: A conceptual Introduction.

xxxiv. New York: Longman. $4^{\text {th }}$ Edition.

xxxv. Mayer, R. \& Hegarty, M. (1996). The process of understanding mathematical problems. In R.

xxxvi. Stemberg \& T. Ben-Zeev (Eds). The Nature of Mathematical thinking, Mahwah NJ: Kurina, F. (1989) The Art to See in Mathematics. Praha SPN. Czech

xxxvii. Lawrence Erlbaum associates.

xxxviii. Mayer, R. E. (2003). Learning and Instruction. Person Education, Inc; Upper Suddle river(pp. 287-288).

xxxix. Miller C. D. \& Margaret I. L. (1998). College Algebra (5th Edition). Dallas: Harper Collin publishers.

xl. Mosston, M. (1972), Teaching: From Command to Discovery. Belmont, California: Wadswort publishing.

xli. Mosston, M., \& Ashworth, S. (2002). Teaching physical education (5th ed.). San Francisco, CA: Benjamin Cummings.

xlii. NCTM, (2000). Principles and Standards for School Mathematics. Reston Virginia: National Council of Teachers of Mathematics

xliii. Newman, A. (1983). The Newman language of mathematics kit- Strategies for diagnosis and remediation. Sydney, Australia: Harcourt Brace Jovanovich Group.

xliv. Patton, M. Q. (2002). Qualitative research \& Evaluation methods (3rd ed.). Thousand. Oaks, CA:

xlv. Piaget, J. (1965). The Child's Conception of Number. New York: W. W. Norton and Company.

xlvi. Polya, G. (1962) Mathematical Discovery (Vol 1) New York, NY: Wiley Schoenfeld, A. H. (1985). Mathematical problem solving. Orlando, FL: Academic Press. 
xlvii. Sriraman, B, \&Lesh, R. (2007). A Conversation with Zoltan Dienes. Mathematical Thinking and Learning 9

xlviii. Stanic, G., \& Kilpatrick, J. (1989). Historical Perspectives on Problem Solving in the

xlix. Mathematics Curriculum. In R. I. Charles \& E. A. Silver (Eds.), The teaching and assessing of mathematical problem solving (pp. 1-22). Reston, VA:

l. Verschaffel, L., Greer, B. and De Corte, E. (2000). Making Sense of Word Problems. Lisse, the Netherlands, Swets and Zeithinger.

Questions for the Pre-test

\section{Appendix}

- The sum of two numbers is 54. One exceeds the other by 14. Find the numbers

- Twice a certain number plus three times the same number is 35 . Find the number.

- Afi is four times as old as her daughter. If the sum of their ages is 60 years, find the age of her daughter

- $\quad$ Find the solution set of $\frac{1}{5}(2+y)=\frac{1}{2}(y-1)$

- Solve the equation $\frac{2 x+3}{2}-\frac{x+1}{3}=\frac{x-3}{6}$

Questions for the Post-test

1. Maame Esi bought 6 plates and 10 drinking cups from a shop. A plate cost her $\$ 20$ more than a drinking cup. If she spent $\$ 1080$ altogether, how much did a plate and a drinking cup cost?

2. A man walked 5 kilometers, and then travelled a certain distance by Nissan Urvan bus, and twice as far by train. If the whole journey was 104 kilometers, how far did he travel by bus

3. Kofi is now five times as old as Kweku. In ten years' time Kofi will be three times as old as Kweku. How old are they?

4. The sum of three numbers is 81 . The second number is twice the first number, and the third number is six more than the second number. Find the numbers.

5. The perimeter of a rectangle is $216 \mathrm{~cm}$. It is twice as long as it is wide. Find the length and the width of the rectangle. 